\title{
Solubility and Diffusion Coefficient of Hydrogen Sulphide in Polyethylene Glycol 400 from 100 to $140^{\circ} \mathrm{C}$
}

\author{
N. Ferrando*, P. Mougin, D. Defiolle and H. Vermesse \\ Institut français du pétrole, IFP, Thermodynamic and Molecular Simulation Department, \\ 1-4 avenue de Bois-Préau, 92852 Rueil-Malmaison Cedex, France \\ e-mail: nicolas.ferrando@ifp.fr - pascal.mougin@ifp.fr - denis.defiolle@ifp.fr - helene.vermesse@ifp.fr \\ * Corresponding author
}

Résumé - Solubilité et coefficient de diffusion du sulfure d'hydrogène dans le polyéthylène glycol 400 de 100 à $140^{\circ} \mathrm{C}$ - La limitation des rejets de gaz à effet de serre et de gaz acides, comme le sulfure d'hydrogène, est désormais une préoccupation majeure lors de la conception de procédés industriels. Dans ce contexte, $\mathrm{Clauspol}^{\circledR}$ est un procédé de traitement des gaz de queue du Claus qui répond à ce besoin en atteignant des taux de récupération en soufre élevés. Il consiste à convertir chimiquement $\mathrm{H}_{2} \mathrm{~S}$ et $\mathrm{SO}_{2}$ en soufre élémentaire dans un solvant composé de polyéthylène glycol 400 . L'optimisation de ce procédé requiert une connaissance précise de la solubilité et de la diffusivité des gaz dans ce solvant. Ainsi, ce travail présente dans le cas de $\mathrm{H}_{2} \mathrm{~S}$ des mesures expérimentales de ces grandeurs et leur modélisation dans les conditions opératoires du procédé. Les données de solubilité sont modélisées avec l'équation d'état de Sanchez-Lacombe avec un simple coefficient d'interaction binaire indépendant de la température. Les coefficients de diffusion sont déterminés en appliquant le modèle Infinite-Acting sur la courbe expérimentale de la chute de pression. Ils apparaissent être inversement proportionnels à la viscosité du solvant.

\footnotetext{
Abstract - Solubility and Diffusion Coefficient of Hydrogen Sulphide in Polyethylene Glycol 400 from 100 to $140^{\circ} \mathrm{C}$ - The limitation of greenhouse and sour gas emissions in the atmosphere, such as hydrogen sulphide, is nowadays a major preoccupation in industrial processes. In this context, the Clauspol ${ }^{\circledR}$ process is a Claus tail gas treatment able to respond to this challenge of reaching high sulphur recovery. It consists of chemically converting $\mathrm{H}_{2} \mathrm{~S}$ and $\mathrm{SO}_{2}$ into elementary sulphur in a polyethylene glycol 400 solvent. The optimisation of the process design requires a precise knowledge of both the solubility and diffusivity of these gases in this solvent. Hence, this work presents, in the case of $\mathrm{H}_{2} \mathrm{~S}$, experimental measurements and modelling of these data in the process operating conditions. The solubility data are modelled by the Sanchez-Lacombe equation of state with a single temperatureindependent binary interaction coefficient. The diffusion coefficients are determined by applying the Infinite-Acting model to the experimental pressure decay curve. It is found to be inversely proportional to the viscosity of the solvent.
} 


\section{INTRODUCTION}

The limitation of greenhouse and sour gas emissions in the atmosphere is nowadays a major preoccupation in industrial processes. In a refining plant, many rich hydrogen sulphide effluents are generated and have to be treated due to the high toxicity of this gas. The future specifications on the sulphur content of fuel blends will become more severe, and hydrotreatment units will consequently produce larger amounts of hydrogen sulphide. At the same time, the specifications on the global sulphur gases emitted into the atmosphere are becoming more and more restrictive. Therefore, the actual hydrogen sulphide treatment processes have to be improved in order to achieve these goals.

The Clauspol ${ }^{\circledast}$ process is one of the processes aiming to achieve a very high sulphur recovery [1-4]. It is a Claus tail gas treatment whose goal is to chemically convert hydrogen sulphide and sulphur dioxide into elementary sulphur and water, according to the reaction:

$$
2 \mathrm{H}_{2} \mathrm{~S}+\mathrm{SO}_{2} \leftrightarrow 3 / \mathrm{x} \mathrm{S}+2 \mathrm{H}_{2} \mathrm{O}
$$

This reaction occurs in a non-volatile liquid organic solvent, polyethylene glycol 400 (PEG 400). Hydrogen sulphur and sulphur dioxide are absorbed in the solvent before reacting at a temperature slightly above the sulphur melting point, around $120^{\circ} \mathrm{C}$. Hence, to simulate this process exactly and to improve its performance, it is necessary to know precisely some physical data, such as the solubility and the diffusivity of gas in the solvent.

In this work, we first present new experimental solubility data of hydrogen sulphide in PEG 400 between 100 and $140^{\circ} \mathrm{C}$, i.e. in the process operating conditions range. These data are modelled with the Sanchez-Lacombe equation of state [5] with a single temperature-independent binary parameter. As the hydrogen sulphide contents are very low in the vapour phase, we focused on the Henry area of the phase diagram, and the Henry constants are predicted with this model. Secondly, the diffusion coefficient of $\mathrm{H}_{2} \mathrm{~S}$ in this solvent is experimentally estimated with the same apparatus. The methodology and the temperature dependence of this coefficient are highlighted.

\section{EXPERIMENT}

\subsection{Apparatus and Material}

The experimental setup used in this work has been described elsewhere $[6,7]$. We only present here the main points of the apparatus schemed in Figure 1.

The Clauspol ${ }^{\oplus}$ process is licensed by Prosernat, $100 \%$ IFP subsidiary (http://www.prosernat.com), and is part of Advasulf ${ }^{\mathrm{TM}}$, a complete choice of technologies to reach overall sulphur recovery up to $99.9+\%$.

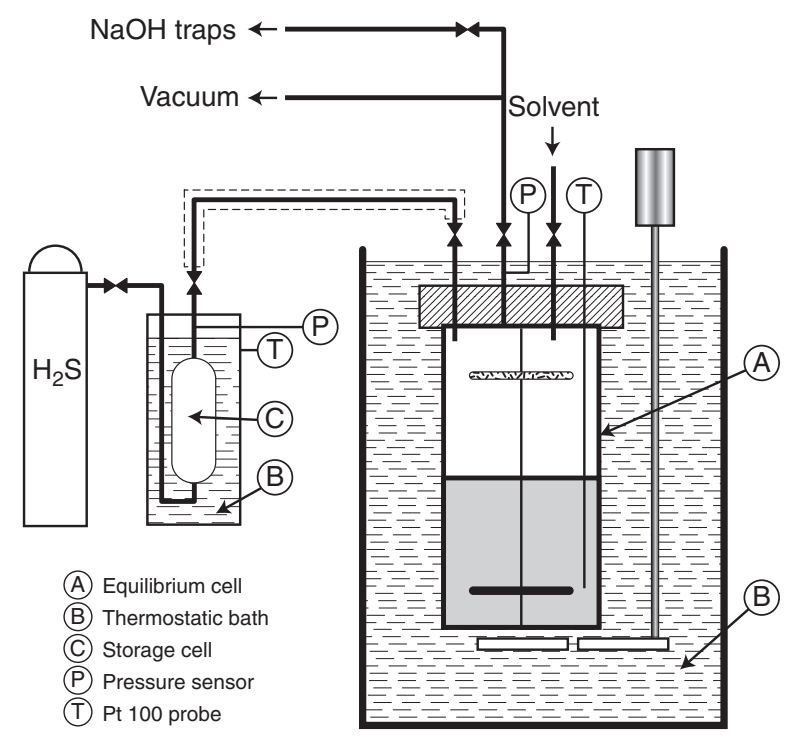

Figure 1

Experimental setup.

A $253.5-\mathrm{cm}^{3}$ static cell made of Hastelloy is immerged in a LAUDA thermostatic liquid bath whose temperature fluctuation does not exceed $0.05 \mathrm{~K}$. Two stirring rotors ensure the homogeneity of liquid and vapour phases. Thermostated tubing links this equilibrium cell to a $169.1-\mathrm{cm}^{3} \mathrm{H}_{2} \mathrm{~S}$ storage tank immerged in a thermostatic liquid bath. Additional tubing is used to link the equilibrium cell either to a vacuum system to allow the degassing of the solvent, or to sodium hydroxyl traps to securely clean the cell after each experiment. A Pt 100 probe measures temperature with an accuracy of $0.03 \mathrm{~K}$. The pressure is measured with a $\mathrm{HBM}^{\circledast} 100 \mathrm{bar}$ pressure sensor with an accuracy of $0.015 \mathrm{MPa}$ or with a $\mathrm{HBM}^{\circledast} 20$ bar pressure sensor with an accuracy of $0.0028 \mathrm{Mpa}$, depending on the experimental pressure range.

Hydrogen sulphide was provided by Air Liquid, with a purity of $99.7 \%$. Polyethylene glycol 400 was provided by BASF. A Karl-Fisher titration indicated a water content of 0.34 weight percent in the polymer. Hence, a dehydration step is included in the experimental procedure described further.

\subsection{Experimental Procedure}

To measure solubility and estimate diffusion of $\mathrm{H}_{2} \mathrm{~S}$ in PEG 400 , a three-step experimental procedure is performed.

The first step is the solvent dehydration in order to eliminate any traces of water dissolved in the commercial PEG 400. The equilibrium cell is filled with a well-known amount 
of solvent (around $100 \mathrm{~g}$ ). The temperature is then increased to $120^{\circ} \mathrm{C}$, and a vacuum is made in the cell for degassing it. At this temperature, the vapour pressure of polyethylene glycol 400 is about $1 \mathrm{~Pa}$ according to the manufacturer. Hence, no loss of polymer is expected during this purification step. From the vacuum pressure in the cell, $P^{i n i}$, the residual dissolved water is estimated in terms of molar fraction, $x_{\text {water }}$, from Raoult's law:

$$
x_{\text {water }}=\frac{P^{\text {ini }}}{P_{\text {water }}^{\sigma}(T)}
$$

where denotes the vapour pressure of water, computed from the DIPPR database [8]. Basically, this procedure allows one to decrease the water content by up to 0.04 weight percent.

The diffusion acquisition is the second step of the measurement. The temperature of the thermostated bath is adjusted to the desired operating temperature. No agitation of the cell is performed in this measurement procedure. At the initial time, a gas injection is performed and the pressure decay is recorded during a three-day period. The precise amount of hydrogen sulphide introduced, named $n_{\mathrm{H}_{2} \mathrm{~S}}^{0}$ is determined by a mass balance in the storage bottle before and after the injection:

$$
n_{\mathrm{H}_{2} \mathrm{~S}}^{0}=\frac{V_{s t}}{R}\left(\frac{P_{s t}^{\text {initial }}}{Z\left(T_{s t}^{\text {initial }}, P_{s t}^{\text {initial }}\right) \cdot T_{s t}^{\text {initial }}}-\frac{P_{s t}^{\text {final }}}{Z\left(T_{s t}^{\text {final }}, P_{s t}^{\text {final }}\right) \cdot T_{s t}^{\text {final }}}\right)
$$

where $V, T$ and $P$ denote volume, temperature and pressure, respectively. $R$ is the ideal gas constant $(R=8.31451$ $\mathrm{J} / \mathrm{mol} / \mathrm{K}$ ), and $Z$ the compressibility factor calculated from the Goodwin pure component equation of state [9]. The superscripts initial and final denote the time before and after the gas injection, respectively. The subscript st refers to the storage bottle. During the first two hours, the pressure in the cell is stored on a computer disk every five seconds. After that, it is stored every five minutes. The final pressure decay curve is exploited according to the model described further.

Finally, the third step of the experimental procedure is the hydrogen sulphur solubility measurements. Once the previously described three-day period is ended, the agitation rotors are started to completely reach thermodynamic equilibrium. The equilibrium pressure is noted, and a new gas injection is performed. The hydrogen sulphur amount injected is always calculated from the equation.

The amount of hydrogen sulphur dissolved in the solvent after each gas injection is determined by a mass balance:

$$
n_{\mathrm{H}_{2} \mathrm{~S}}^{L}=n_{\mathrm{H}_{2} \mathrm{~S}}^{0}-n_{\mathrm{H}_{2} \mathrm{~S}}^{V}
$$

where the superscripts $L$ and $V$ refer to the liquid and the vapour phases.

The amount of hydrogen sulphur in the vapour phase is calculated from the relation:

\begin{tabular}{|c|c|c|c|c|}
\hline$T$ & $P$ & $\times \mathrm{H}_{2} \mathrm{~S}$ exp. & $\times \mathrm{H}_{2} \mathrm{~S}$ calc. & $\mathrm{AAD}^{1}$ \\
\hline $\mathrm{K}$ & bar & mol.frac. & mol.frac. & $\%$ \\
\hline 373.15 & 1.18 & 0.062 & 0.057 & 6.97 \\
\hline 373.15 & 2.75 & 0.128 & 0.126 & 2.01 \\
\hline 373.15 & 4.43 & 0.190 & 0.190 & 0.34 \\
\hline 373.15 & 6.03 & 0.243 & 0.244 & 0.41 \\
\hline 373.15 & 7.29 & 0.280 & 0.283 & 0.98 \\
\hline 373.15 & 8.31 & 0.308 & 0.312 & 1.27 \\
\hline 393.15 & 1.83 & 0.070 & 0.066 & 5.93 \\
\hline 393.15 & 3.87 & 0.133 & 0.132 & 0.84 \\
\hline 393.15 & 5.87 & 0.189 & 0.189 & 0.33 \\
\hline 393.15 & 7.04 & 0.218 & 0.219 & 0.66 \\
\hline 393.15 & 8.53 & 0.252 & 0.256 & 1.29 \\
\hline 393.15 & 9.59 & 0.276 & 0.280 & 1.38 \\
\hline 413.15 & 1.81 & 0.049 & 0.051 & 4.44 \\
\hline 413.15 & 3.16 & 0.084 & 0.087 & 3.23 \\
\hline 413.15 & 4.56 & 0.119 & 0.121 & 1.44 \\
\hline 413.15 & 6.02 & 0.152 & 0.154 & 1.80 \\
\hline 413.15 & 7.18 & 0.177 & 0.179 & 1.53 \\
\hline 413.15 & 8.68 & 0.208 & 0.210 & 1.14 \\
\hline \multicolumn{5}{|c|}{$A A D=\frac{\mid \text { Exp.value }- \text { Calc.value } \mid}{\text { Exp.value }} \cdot 100$} \\
\hline
\end{tabular}

TABLE 1

Table of the experimental and calculated solubility of $\mathrm{H}_{2} \mathrm{~S}$ in PEG 400

where the superscript eq refers to the thermodynamic equilibrium state, and the subscript cell refers to the equilibrium cell. The vapour pressure of the solvent is assumed to be negligible.

The volume of the vapour phase is known from a volume balance:

$$
V^{V}=V_{c e l l}-V^{L}
$$

The volume of the liquid phase is calculated from the mass and density of the solvent, assuming that the variation in volume due to the dissolved gas is negligible:

$$
V^{L}=\frac{m_{s}}{\rho_{s}}
$$

where $m_{s}$ is the mass of the solvent and $\rho_{s}$ its density at the operating temperature. Preliminary work was done to determine the density of the dehydrated polyethylene glycol 400 used in this work according to the temperature:

$$
\rho_{s}\left(\mathrm{~kg} / \mathrm{m}^{3}\right)=-0.9037 \cdot T(\mathrm{~K})+1.394 \cdot 10^{3}
$$




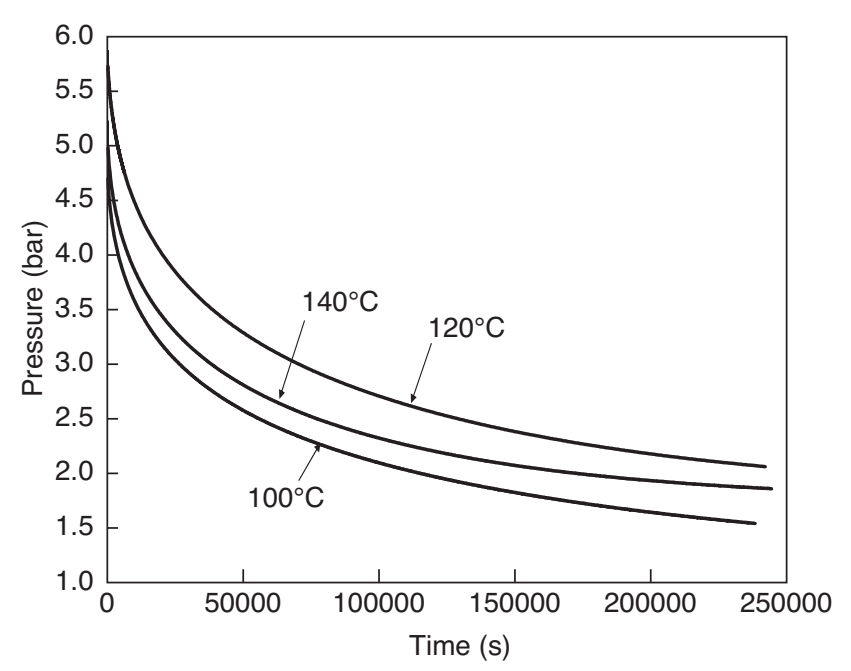

Figure 2

Pressure decay measurement during $\mathrm{H}_{2} \mathrm{~S}$ diffusion in PEG 400 at 100,120 and $140^{\circ} \mathrm{C}$.

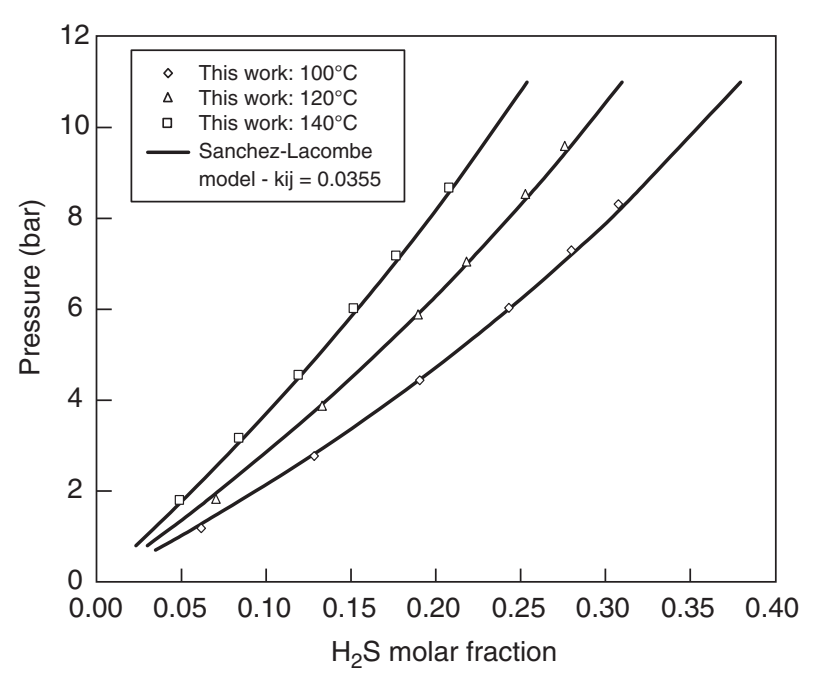

Figure 3

Experimental and calculated solubility of $\mathrm{H}_{2} \mathrm{~S}$ in PEG 400 at 100,120 and $140^{\circ} \mathrm{C}$.

\subsection{Experimental Results}

Three isotherms are investigated: 100,120 and $140^{\circ} \mathrm{C}$. For each isotherm, the pressure decay is measured, and a series of five additional injections are carried out. Figure 2 shows the pressure decay experimental curve for each temperature.

Figure 3 plots the hydrogen solubility for each isotherm for pressure from about 1 to $10 \mathrm{bar}$. The experimental points are listed in Table 1 . There are no other data of $\mathrm{H}_{2} \mathrm{~S}$ solubility in PEG 400 available in the literature. Hence, no direct comparison or deviation estimation are possible. However, previous experiments on $\mathrm{H}_{2} \mathrm{~S}$ solubility in the same experimental setup, but in another solvent, have been reported in the literature [10]. The reproducibility of these experiments was estimated at about $2.5 \%$. We assume here the same uncertainty for our experimental points.

\section{SOLUBILITY MODELLING}

$\mathrm{H}_{2} \mathrm{~S}$ solubility in PEG 400 is modelled with the SanchezLacombe equation of state [5]:

$$
\bar{P}=-\bar{T}\left[\ln (1-\bar{\rho})+\left(1-\frac{1}{r}\right) \bar{\rho}\right]-\bar{\rho}^{2}
$$

where $\bar{P}, \bar{T}$ and $\bar{\rho}$ are the reduced pressure, temperature and density given by:

$$
\bar{P}=\frac{P v}{\varepsilon^{*}}
$$

$$
\begin{gathered}
\bar{T}=\frac{R T}{\varepsilon^{*}} \\
\bar{\rho}=\rho r v^{*}
\end{gathered}
$$

where $\varepsilon^{*}, v^{*}$ and $r$ are the microscopic parameters specific to each pure component, corresponding to the interaction energy between non-bonded molecular segments, the volume of a lattice site, and the number of lattice sites occupied by the molecule, respectively. For a mixture of $c$ components, we adopt the following mixing rules:

$$
\begin{gathered}
v^{*}=\sum_{i=1}^{c} \phi_{i} v_{i i}^{*} \\
\varepsilon^{*} v^{*}=\sum_{i=1}^{c} \sum_{j=1}^{c} \phi_{i} \phi_{j} v_{i j}^{*} \varepsilon_{i j}^{*}
\end{gathered}
$$

with

$$
\begin{gathered}
\phi_{i}=\frac{x_{i} r_{i}}{r} \\
v_{i j}^{*}=\frac{1}{2}\left(v_{i}^{*}+v_{j}^{*}\right) \\
\varepsilon_{i j}^{*}=\left(\varepsilon_{i}^{*} \varepsilon_{j}^{*}\right)^{1 / 2}\left(1-k_{i j}\right)
\end{gathered}
$$

where $k_{i j}$ is an empirical binary interaction parameter.

For polyethylene glycol 400, several sets of pure component parameters, adjusted on PVT data, are available. We choose to use the parameters proposed by Sanchez and Panayiotou [11]. For hydrogen sulphide, two sets of 


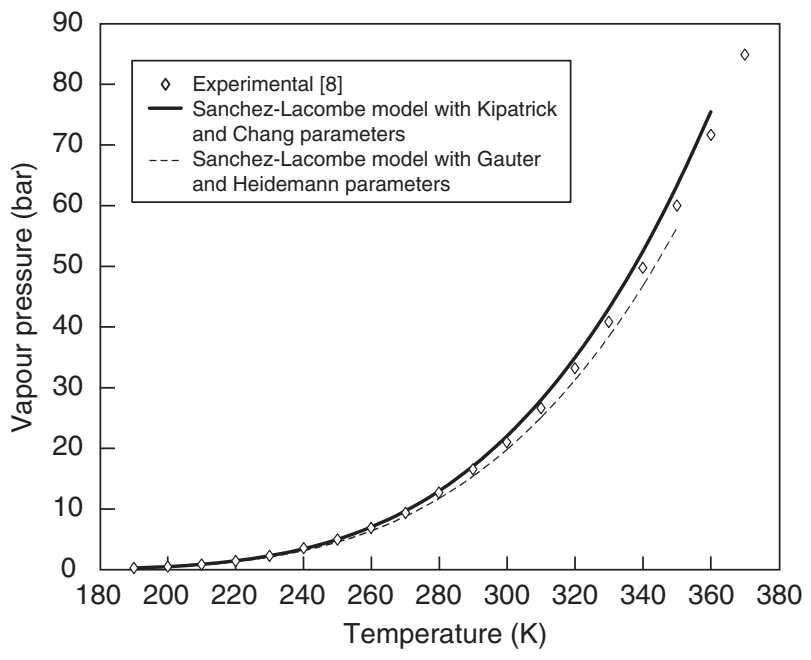

Figure 4

Experimental and calculated vapour pressure of pure $\mathrm{H}_{2} \mathrm{~S}$. Experimental data are from the DIPPR database [8]. Modelled data are calculated with the Sanchez-Lacombe equation of state with the Kilpatrick and Chang [12] and the Gauter and Heidemann [13] parameter sets.

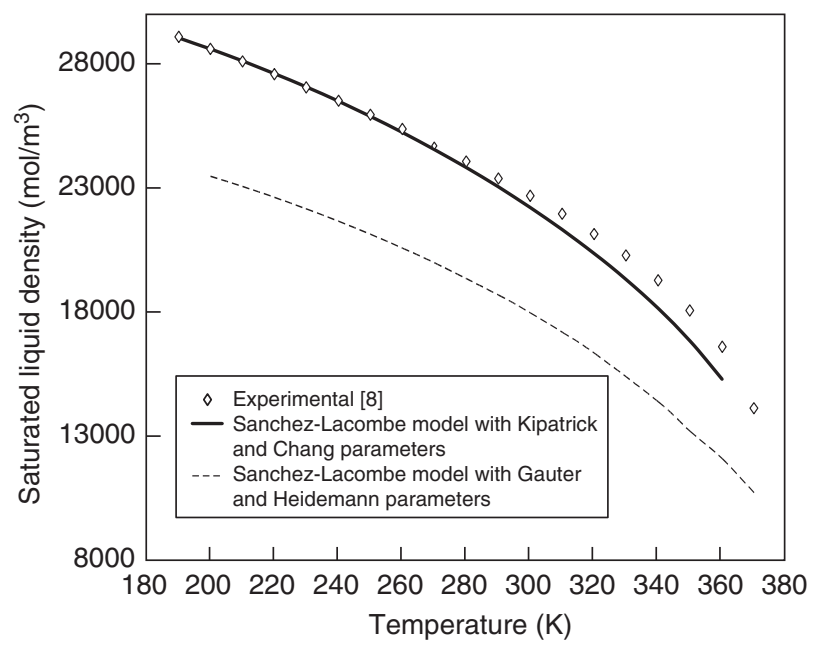

Figure 5

Experimental and calculated saturated liquid density of pure $\mathrm{H}_{2} \mathrm{~S}$. Experimental data are from the DIPPR database [8]. Modelled data are calculated with the Sanchez-Lacombe equation of state with the Kilpatrick and Chang [12] and the Gauter and Heidemann [13] parameter sets.

parameters are found: one proposed by Kilpatrick and Chang [12] adjusted on experimental data of the pure component properties, and another determined from a correlation proposed by Gauter and Heidemann [13] based on the critical properties. As shown in Figures 4 and 5, it is found that the set proposed by Kilpatrick and Chang naturally allows a better prediction of both vapour pressure (deviation about 3\%) and saturated liquid density (deviation about $2 \%$ ) of pure $\mathrm{H}_{2} \mathrm{~S}$. As a consequence, we choose to use this set of parameters for this compound. Finally, Table 2 resumes the purecomponent Sanchez-Lacombe parameters used in this work.

TABLE 2

Pure-component Sanchez-Lacombe parameters of PEG 400 and $\mathrm{H}_{2} \mathrm{~S}$

\begin{tabular}{c|c|c|c|c}
\hline Compound & $r$ & $\varepsilon^{*}(\mathrm{~J} / \mathrm{mol})$ & $v^{*}\left(\mathrm{~m}^{3} / \mathrm{mol}\right)$ & Ref. \\
\hline PEG 400 & 30.35 & 5495.55 & $1.1215 .10^{-5}$ & {$[11]$} \\
\hline $\mathrm{H}_{2} \mathrm{~S}$ & 6.3540 & 3076.48 & $4.9080 .10^{-6}$ & {$[12]$} \\
\hline
\end{tabular}

Additionally, a binary interaction parameter is adjusted on our experimental data to reproduce them best. It is found that a single independent-temperature coefficient is sufficient to achieve a good accuracy. The optimal value is:

$$
k_{\mathrm{H}_{2} \mathrm{~S} / P E G 400}=0.0355
$$

The modelled data are plotted in Figure 3 and reported in Table 1 . The average deviation between model and experiments is globally about $2.0 \%$.

The model performed being accurate at predicting the solubility data, it is used to calculate the Henry constant of $\mathrm{H}_{2} \mathrm{~S}$ in the solvent. By definition, the Henry constant is:

$$
H_{i}=\lim _{x_{i} \rightarrow 0}\left(\frac{P \varphi_{i} y_{i}}{x_{i}}\right)
$$

where $\varphi_{i}$ denotes the fugacity coefficient of the solute in the vapour phase, and $x_{i}$ and $y_{i}$ its molar fraction in the liquid and the vapour phases, respectively. As the solvent can be assumed to be non-volatile, the molar fraction of $\mathrm{H}_{2} \mathrm{~S}$ in the vapour phase is equal to one. The fugacity coefficient can be extracted from the Sanchez-Lacombe equation of state. Its analytic expression is the following [14]:

$$
\begin{gathered}
\ln \varphi_{i}=-\ln z+r_{i}\left[-2 \frac{\bar{\rho}}{\bar{T}}-\ln (1-\bar{\rho})\right]+ \\
\left(\frac{z-1}{r}\right)\left[\frac{n r}{v^{*}}\left(\frac{\partial v^{*}}{\partial n_{i}}\right)_{n_{j}}\right]-\frac{\bar{\rho}}{\bar{T}}\left[\frac{n r}{\varepsilon^{*}}\left(\frac{\partial \varepsilon^{*}}{\partial n_{i}}\right)_{n_{j}}\right]
\end{gathered}
$$

with

$$
\begin{gathered}
z=\frac{P v}{R T} \\
n=\sum_{i=1}^{c} n_{i}
\end{gathered}
$$




$$
r=\sum_{i=1}^{c} x_{i} r_{i}
$$

Hence, the fugacity coefficient at infinite dilution (i.e. when the concentration of the solute leads to zero) is given by:

$$
\begin{gathered}
\ln \varphi_{i}^{\infty}=-\ln z^{\infty}+r_{i}\left[-2 \frac{\bar{\rho}^{\infty}}{\bar{T}^{\infty}}-\ln \left(1-\bar{\rho}^{\infty}\right)\right]+ \\
\left(\frac{z^{\infty}-1}{r_{s}}\right) \lim _{n_{1} \rightarrow 0}\left[\frac{n r}{v^{*}} \frac{\partial v^{*}}{\partial n_{i}}\right]-\frac{\bar{\rho}^{\infty}}{\bar{T}^{\infty}} \lim _{n_{1} \rightarrow 0}\left[\frac{n r}{\varepsilon^{*}} \frac{\partial \varepsilon^{*}}{\partial n_{i}}\right]
\end{gathered}
$$

where, with the chosen mixing rules:

$$
\begin{aligned}
& \lim \left[\frac{n r}{v^{*}} \frac{\partial v^{*}}{\partial n_{i}}\right]=\frac{1}{v_{s}^{*}}\left[r_{i}\left(-v_{s}^{*}+v_{i}^{*}\right)\right] \\
& \lim \left[\frac{n r}{\varepsilon} \frac{\partial \varepsilon^{*}}{\partial n_{i}}\right]=\frac{1}{\varepsilon_{s}^{*} v_{s}^{*}}\left[2 r _ { i } \left(-\varepsilon_{s}^{*} v_{s}^{*}+\right.\right. \\
&\left.\left.\frac{1}{2} \sqrt{\varepsilon_{s}^{*} \varepsilon_{i}^{*}}\left(1-k_{i s}\right)\left(v_{s}^{*}+v_{i}^{*}\right)\right)\right]-\frac{1}{v_{s}^{*}}\left[r_{i}\left(-v_{s}^{*}+v_{i}^{*}\right)\right] \\
& \bar{\rho}^{\infty}=\frac{r_{s} v_{s}^{*}}{v_{s}^{\sigma}} \\
& \bar{T}^{\infty}=\frac{R T}{\varepsilon_{s}^{*}} \\
& z^{\infty}=\frac{P_{s}^{\sigma} v_{s}^{\sigma}}{R T}
\end{aligned}
$$

The saturated molar volume of the pure solvent $v_{s}^{\sigma}$ is computed from the equation of state. Finally, the Henry constants of hydrogen sulphide in polyethylene glycol for the three temperatures investigated are given in Table 3. According to the uncertainty of the experimental data and the precision of the model, we assume an uncertainty of about $5 \%$ for these Henry constant values.

TABLE 3

Henry constant of $\mathrm{H}_{2} \mathrm{~S}$ in PEG 400 at 100,120 and $140^{\circ} \mathrm{C}$

\begin{tabular}{c|c}
\hline$T(\mathrm{~K})$ & $H(\mathrm{bar} / \mathrm{mol}$. frac. $)$ \\
\hline 373.15 & 19.59 \\
\hline 393.15 & 26.15 \\
\hline 413.15 & 33.65 \\
\hline
\end{tabular}

\section{DIFFUSION COEFFICIENT MODELLING}

The diffusion coefficient is determined with an inverse problem methodology, in which the experimental data can be reproduced on the basis of unknown parameters. In our case, the unknown parameter is the diffusion coefficient, and the experimental data are the pressure decay curve. The model used to reproduce this curve is the so-called Infinite-Acting model, largely described by Sheikha et al. [15] in their bibliographic review of diffusion coefficient determination methodologies. The assumptions of the methodology are the following: the system is non-reactive, isothermal conditions are assumed throughout the pressure decay experiment, the solvent is non-volatile, the diffusion coefficient is constant, there is only a diffusion phenomenon which follows Fick's second law, the Henry law can be applied to the gas-liquid equilibrium at the interface, and the liquid phase is a semiinfinite medium.

Following Fick's second law:

$$
D \frac{\partial^{2} C(z, t)}{\partial z^{2}}=\frac{\partial C(z, t)}{\partial t}
$$

where $D$ is the diffusion coefficient, and $C(z, t)$ the dissolved gas concentration in the liquid phase at the depth $z$ in the liquid phase (origin is taken at the gas-liquid interface) and at the time $t$.

A mass balance at the interface $(z=0)$ gives:

$$
-V_{g} \frac{\partial C_{g}(t)}{\partial t}=-S D\left(\frac{\partial C(z, t)}{\partial z}\right)_{z=0}
$$

where $V_{g}$ is the volume of the vapour phase, calculated from the equation, $C_{g}(t)$ the gas concentration in the vapour phase, and $S$ the surface of the gas-liquid interface known from the geometry of the equilibrium cell.

The Henry law at the gas-liquid interface is:

$$
H=\frac{P}{\bar{v} \cdot C(0, t)}
$$

where $\bar{v}$ is the molar volume of the liquid phase, assumed to be equal to the molar volume of the solvent (as for the solubility data calculation methodology, the variation in volume due to the dissolved gas is neglected).

With the relation:

$$
P=Z(T, P) C_{g}(t) R T
$$

the Henry law expression is equivalent to:

$$
C_{g}(t)=\alpha \cdot C(0, t)
$$

with

$$
\alpha=\frac{H \bar{v}}{Z(T, P) R T}
$$

This differential equations system is solved using the Laplace transforms. In the mathematical resolution, it is assumed that the $\alpha$ parameter does not depend on the time. 
Because the pressure difference between the initial and the final time of the pressure decay curve is relatively small (3 bar at max.), this assumption is realistic. Rigorously, after the initial degassing process, the pressure in the cell is equal to the vapour pressure of the solvent $P_{b}$. Because of the extremely low volatility of PEG 400 , it is in fact the vapour pressure of the traces of water in this solvent. Therefore, it is necessary to work with relative pressures. Finally, the expression of pressure as a function of time is:

$$
\frac{P(t)-P_{b}}{P(0)-P_{b}}=\frac{Z(T, P(t))}{Z(T, P(0))} \exp \left(\phi^{2}\right) \cdot \operatorname{erfc}(\phi)
$$

where $P(0)$ is the pressure just after the gas introduction, and with:

$$
\phi=\sqrt{\frac{D t}{\alpha^{2} L^{2}}}
$$

and $L$ is the height of the vapour phase, calculated with:

$$
L=\frac{V_{g}}{S}
$$

At this step, the methodology consists of fitting the coefficient diffusion in order to reproduce well the experimental pressure decay curve. However, due to the non-linearity of the equation, the adjustment method is complex. Thus, we should modify equation to obtain a linear form. Moreover, it is important to note that this Infinite-Acting model gives for an infinite time a pressure equal to zero and not, as we can expect, equal to the equilibrium pressure. Hence, this model cannot be used in the whole range of time, and has to be employed only at the beginning of the pressure decay curve. The linearisation of equation must allow one to easily determine the validity range of the model.

In this way, we use the methodology proposed by Sheikha et al. [16], consisting of using a development of the erfc function. Indeed, following the mathematical form proposed by Abramovitch [17]:

$$
\operatorname{erfc}(x)=\left(a_{3}[\beta(x)]^{3}+a_{2}[\beta(x)]^{2}+a_{1} \beta(x)\right) \exp \left(-x^{2}\right)+\varepsilon
$$

with

$$
\beta(x)=\frac{1}{a_{4} x+1}
$$

and $a_{1}=0.3480242, a_{2}=-0.0958798, a_{3}=0.7478556, a_{4}=$ $0.47047,|\varepsilon|<2.5 .10^{-5}$. Reporting that in equation, we find:

$$
\frac{P(t)-P_{b}}{P(0)-P_{b}} \cdot \frac{Z(T, P(0))}{Z(T, P(t))}=\left(a_{3}[\beta(\phi)]^{3}+a_{2}[\beta(\phi)]^{2}+a_{1} \beta(\phi)\right)
$$

Such an equation can be reformulated in:

$$
a \phi^{3}+b \phi^{2}+c \phi+d=0
$$

with:

$$
\begin{gathered}
a=a_{4}^{3}\left(\frac{P(t)-P_{b}}{P(0)-P_{b}}\right) \frac{Z(T, P(0))}{Z(T, P)} \\
b=3 a_{4}^{2}\left(\frac{P(t)-P_{b}}{P(0)-P_{b}}\right) \frac{Z(T, P(0))}{Z(T, P)}-a_{1} a_{4}^{2} \\
c=3 a_{4}\left(\frac{P(t)-P_{b}}{P(0)-P_{b}}\right) \frac{Z(T, P(0))}{Z(T, P)}-a_{2} a_{4}-2 a_{1} a_{4} \\
d=\left(\frac{P(t)-P_{b}}{P(0)-P_{b}}\right) \frac{Z(T, P(0))}{Z(T, P)}-a_{3}-a_{2}-a_{1}
\end{gathered}
$$

Equation 42 has only one real root. For each time $t$, this root, $\phi$, is found in solving this equation and the curve giving this root as a function of the square root of time is plotted. According to the relation (37), this curve should be a straight line passing through the origin. An example of such a curve is shown in Figure 6, for the experimental measurements at $140^{\circ} \mathrm{C}$. Similar curves are obtained for the two other temperatures investigated $\left(100\right.$ and $\left.120^{\circ} \mathrm{C}\right)$.

Then, knowing the Henry constant at the operating temperature (Table 3) and the geometry characteristics of the cell, the slope of this curve in its linear part directly gives the diffusion coefficient. Moreover, the time limit above which the Infinite-Acting model can no longer be applied is identified when this curve can no longer be considered as a straight line. For example, in Figure 6, we can see that the experimental curve can no longer be considered as linear from a

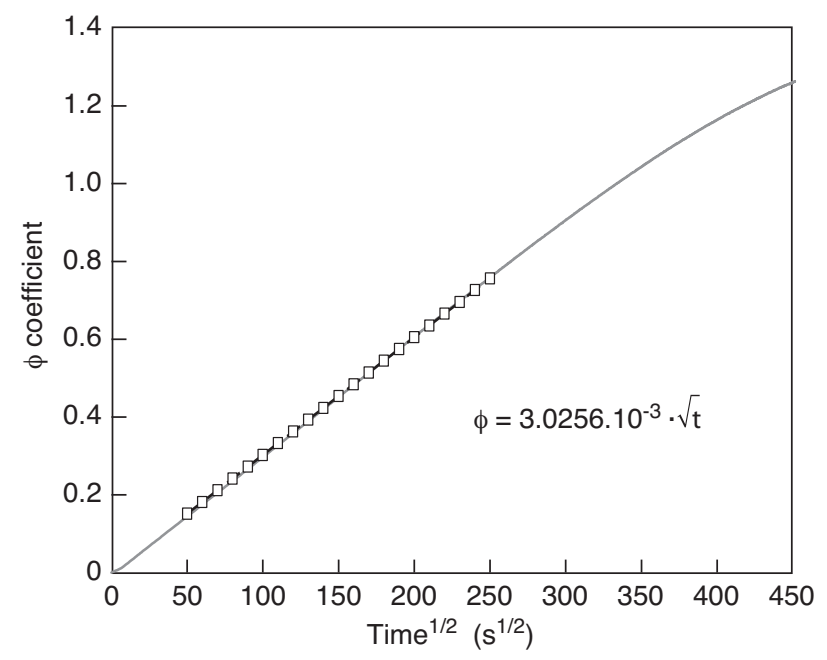

Figure 6

Evolution of the real root, $\phi$, of Equation 43 versus time (solid light line), and linear regression of the linear part of this curve (dotted dark line with open squares) at $140^{\circ} \mathrm{C}$. 
square root of time of about $350 \mathrm{~s}^{1 / 2}$. This example shows that we consider a decay of pressure by a factor of around 2 to deduce the diffusion coefficient. Hence, not only the initial slope of the pressure decay curve is used. Moreover, in this example, after 34 hours the curve still follows Fick's law, and no convection phenomenon is noticed. For each temperature, the calculated diffusion coefficient is summarised in Table 4. With this methodology, the diffusion coefficient appears to be very sensitive to the Henry constant value. According to the uncertainty of our previously determined Henry constants, we assume an uncertainty of about $10 \%$ in the diffusion coefficient. It is also important to note that according to the large number of assumptions and the simplification in the mathematical treatment of the curve, these values cannot be considered as rigorous measurements of the diffusion coefficient, but only as estimations.

TABLE 4

Diffusion coefficient of $\mathrm{H}_{2} \mathrm{~S}$ in PEG 400 at 100,120 and $140^{\circ} \mathrm{C}$

\begin{tabular}{c|c}
\hline$T(\mathrm{~K})$ & $10^{9} D\left(\mathrm{~m}^{2} / \mathrm{s}\right)$ \\
\hline 373.15 & 1.6853 \\
\hline 393.15 & 2.2270 \\
\hline 415.15 & 3.6214 \\
\hline
\end{tabular}

In Figure 7, the diffusion coefficient is plotted as a function of the viscosity of the solvent. This last property is calcu-

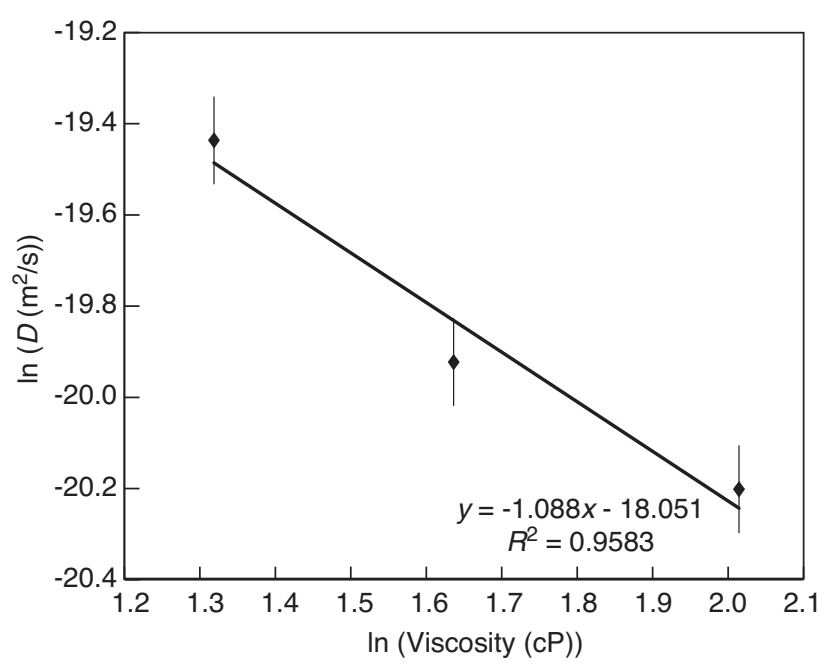

Figure 7

Variation in the diffusion coefficient of $\mathrm{H}_{2} \mathrm{~S}$ in PEG 400 with the viscosity of the solvent. lated for the three temperatures investigated from the correlation proposed by Cruz et al. [18], after having preliminarily checked with some experiments that it is applicable to the PEG 400 used in this work.

Taking into account the experimental uncertainties, this figure shows that the diffusion coefficient of hydrogen sulphide in PEG 400 is inversely proportional to the viscosity of the solvent. This observation is consistent with the StockesEinstein equation, which gives the general form of the theoretical evolution of the diffusion coefficient with viscosity based on hydrodynamic theory, and which states the inversely proportionality relation between these physical properties [19].

\section{CONCLUSION}

In this work, new experimental data of the solubility and diffusion coefficient of hydrogen sulphide in PEG 400 were measured from 100 to $140^{\circ} \mathrm{C}$. The solubility data are accurately modelled with the Sanchez-Lacombe equation of state with a single temperature-independent binary interaction coefficient. Simultaneously, the diffusion coefficients are estimated by applying the Infinite-Acting model to the experimental pressure decay curve. They are found to be inversely proportional to the viscosity of PEG 400.

\section{ACKNOWLEDGEMENTS}

The authors gratefully acknowledge J.P. Ballaguet, A. Barreau and C. Lefebvre for their help with and advice on this work. This work was supported by Prosernat.

\section{REFERENCES}

1 Benayoun B., Dezael C., Lecomte F., Ray J.L. (1996) Improve your Claus Sulfur Recovery with a Titanium Dioxide Catalyst and the new Clauspol 99.9 Tail Gas Treatment, Sulfur, Vancouver, Canada, October 20-23.

2 Streicher C. (1997) Clauspol achieves $99.9 \%$ sulfur recovery, Sulfur 250, 60-64.

3 Barrere-Tricca C., Margotin J.P., Smith D.H. (2001) Thirty Years of Operating Experience with the Clauspol Process, Oil Gas Sci.Technol.56, 199-206.

4 Ballaguet J.P., Barrere-Tricca C., Streicher C. (2003) Improvments to Tail Gas Treatment Process, Petrol. Technol. Quarterly Q3, 109-115.

5 Sanchez I.C., Lacombe R.H. (1976) An Elemantary Molecular Theory of Classical Fluids. Pure Fluids, J. Phys. Chem. 80, 21, 2352-2362.

6 Habchi Tounsi K.N., Barreau A., Le Corre E., Mougin P., Neau E. (2005) Measurement of Carbon Dioxide Solubility in a Solution of Diethanolamine Mixed with Methanol, Ind. Eng. Chem. Res. 44, 9239-9243.

7 Barreau A., Blanchon le Bouhelec E., Habchi Tounsi K.N., Mougin P., Lecomte F. (2006) Absorption of $\mathrm{H}_{2} \mathrm{~S}$ and $\mathrm{CO}_{2}$ in 
Alkanolamine Aqueous Solution: Experimental Data and Modelling with the Electrolyte-NRTL Model, Oil Gas Sci. Technol. 61, 345-361.

8 BYU DIPPR 801 (2005) Thermophysical properties database public release, January 2005.

9 Goodwin R.D. (1983) Hydrogen Sulfide Provisional Thermophysical Properties from 188 to $700 \mathrm{~K}$ at Pressures to 75 $M P a$, NBSIR 83-1694, National Bureau of Standards.

10 Blanchon le Bouhelec E., Tribouillois E. (2006) Contribution à la thermodynamique de l'absorption des gaz acides $\mathrm{H}_{2} \mathrm{~S}$ et $\mathrm{CO}_{2}$ dans les solvants eau-alcanolamine-méthanol : mesures expérimentales et modélisation, Thèse de doctorat de l'Institut National Polytechnique de Lorraine.

11 Sanchez I.C., Panayiotou C.G. (1994) Equation of State Thermodynamics of Polymer and Related Solutions, in Models for Thermodynamic and Phase Equilibria calculations, Sandler S.I. (Ed.), New-York, p. 207.

12 Kilpatrick P.K., Chang S.H. (1986) Saturated Phase Equilibria and Parameter Estimation of Pure Fluids with Two Lattice-Gas Models, Fluid Phase Equilibria 30, 49-56.

13 Gauter K., Heidemann R.A. (2000) A Proposal for Parametrizing the Sanchez-Lacombe Equation of State, Ind. Eng. Chem. Res. 39, 1115-1117.
14 Neau E. (2002) A consistent method for phase equilibrium calculation using the Sanchez-Lacombe lattice-fluid equation of state, Fluid Phase Equilibr. 203, 133-140.

15 Sheikha H., Pooladi-Darvish M., Mehrotra A.K. (2005) Development of graphical methods for estimating the diffusivity coefficient of gases in bitumen from pressure-decay data, Energ. Fuel. 19, 2041-2049.

16 Sheikha H., Mehrotra A.K., Pooladi-Darvish M. (2006) An inverse solution methodology for estimating the diffusion coefficient of gases in Athabasca bitumen from pressure decay data, $J$. Petrol.Sci. Eng. 53, 189-202.

17 Abramowitz M., Stegun I.A. (1970) Handbook of mathematical functions with formulas, graphs and mathematical tables, NBS, Appl. Math. 55, 1020.

18 Cruz M.S., Chumpitaz L.D.A., Alves J.G.L.F., Meirelles A.J.A. (2000) Kinematic Viscosities of Poly(ethylene glycols), J. Chem. Eng. Data 45, 61-63.

19 Reid R.C., Prausnitz J.M., Poling B.E. (1987) The Properties of Gases and Liquids, McGraw-Hill, Inc., 4th ed.

Final manuscript received in November 2007 Published online in May 2008 